\title{
Unintended fusion in cervical artificial disk replacement: a prospective study on heterotopic ossification, progression, and clinical outcome, with 5-year follow-up
}

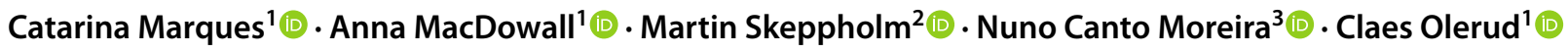

Received: 30 April 2020 / Revised: 24 November 2020 / Accepted: 6 January 2021 / Published online: 20 January 2021

(c) The Author(s) 2021

\begin{abstract}
Purpose Heterotopic ossification (HO) may cause unintended fusion in artificial disk replacement (ADR), failing to preserve motion. The reported incidence of HO varies hugely. This study aimed to determine prevalence of HO, progression, predisposing factors to occurrence and to progression, and potential effect on clinical outcomes.

Methods Eighty-three patients treated with ADRs for cervical radiculopathy at one or two segments were extracted from a previously published RCT. Of the 83 patients, 59 had remaining ADR (79 implants) and sufficiently high-quality X-rays at 5 years of follow-up to allow analysis. HO was graded on plain films according to Mehren/Suchomel. Prevalence, progression, predisposing factors and effect on clinical outcome (Neck Disability Index-NDI) were analyzed.

Results At 2 years, HO was seen in 46/55 ADR implants (84\%), severe enough to affect mobility in 27/55 (49\%). At 5 years, HO was seen in $92 \%$ of 79 implants, severe in $71 \%$. Male sex was a predisposing factor to HO. No predisposing factors to progression were identified. NDI was not affected by the severity of HO.

Conclusion Almost all ADR implants in our study have HO at 5 years of follow-up. Male sex is a risk factor. Severe HO did not affect clinical outcome.

Trial registration Study registered at ISRCTN (registration number: 44347115).
\end{abstract}

Keywords Cervical radiculopathy $\cdot$ Artificial disk replacement $\cdot$ Fusion $\cdot$ Heterotopic ossification $\cdot$ Treatment outcome

\section{Introduction}

Artificial disk replacement (ADR) is frequently used in reconstruction after anterior decompression for cervical radiculopathy, to preserve motion and possibly prevent

Portions of this work were presented in podium presentation form at the CSRS 44th Annual Meeting, Toronto, Canada, December 1-3, 2016, at the CSRS 33th Annual Meeting, Salzburg, Austria, May 24-26, 2017, and at the CSRS 47th Annual Meeting, New York, USA, November 21-23, 2019.

Catarina Marques

catarina.marques@surgsci.uu.se

1 Department of Surgical Sciences, Uppsala University Hospital, Uppsala, Sweden

2 Department for Learning, Informatics, Management and Ethics, Karolinska Institutet, Stockholm, Sweden

3 Pediatric Radiology Section, Department of Clinical Neuroscience (CNS), K8, Karolinska Universitetssjukhuset Solna, Stockholm, Sweden adjacent segment pathology (ASP). Heterotopic ossification (HO) is an unintended event that may lead to spontaneous fusion of the ADR, thus failing to preserve motion $[1,2]$. The prevalence of $\mathrm{HO}$ (ranging in the literature from 0 to $100 \%)[3,4]$, progression over time [5, 6] and predisposing factors [7-9], as well as HO's effect on clinical outcomes [4, 10], are not fully understood. This study aimed to evaluate the prevalence of $\mathrm{HO}$ over a 5 year postoperative period, determine why and how late it may occur, what may possibly cause it to progress, and if and how it affects clinical outcomes.

\section{Patients and methods}

In a previously published RCT on cervical radiculopathy due to degenerative disk disease, 83 patients were operated with ADR (DiscoverTM, DePuy Spine, Johnson and Johnson, Raynham, Massachusetts, U.S.A.) at one or two levels [11, 12]. The patients who had undergone revision surgery or 
not having sufficiently high-quality radiographs at 5 years of follow-up were excluded, leaving 59 patients (79 implants) for analysis for presence and extent of $\mathrm{HO}$ at 2 and 5 years. The patients had been treated with NSAID (ketorolac $25 \mathrm{mg}$ / day) for 10 days postoperatively. Seven patients with twolevel ADRs where one was mobile and the other one stiff were excluded leaving 52 patients for the outcome analysis. Flowchart in Fig. 1. Baseline data are presented in Table 1.

\section{Radiology and grading}

Plain radiographs in flexion, extension and neutral positions were obtained preoperatively, and at 2 and 5 years of followup. CT scans were obtained postoperatively and at 2 years. MRI scans were obtained preoperatively and at 5 years. HO was evaluated on plain films and graded in 5 grades according to Mehren/Suchomel [13] (Fig. 2). The postoperative CT scans were evaluated for facet joint degeneration according to Walraevens [14] and for the positioning of the ADR, dichotomized as either centered or off-centered. Disk degeneration on adjacent segments was graded on MRI scans according to Miyazaki [15].

\section{Clinical outcomes}

The primary outcome measure was the Neck Disability Index (NDI) [16], a patient-reported function score that ranges from 0 to 100 with higher values indicating more severe symptoms. The minimum clinically important difference (MCID) for NDI is 13.4-17.3 [17, 18]. Using baseline NDI and NDI after 5 years, the influence of $\mathrm{HO}$ on the clinical outcome was analyzed, dividing patients into two
Table 1 Patient characteristics at baseline

\begin{tabular}{lll}
\hline Patient characteristic & & \\
\hline Sex & 56 & (\%) Female \\
Age & $45(35-60)$ & Mean (range) \\
Smoking & 31 & (\%) Smoker \\
BMI & $24.9(17.4-34.4)$ & Mean (range) \\
\hline
\end{tabular}

$B M I$ body mass index $\left(\mathrm{kg} / \mathrm{m}^{2}\right)$

groups: (1) arthroplasties with light or no $\mathrm{HO}$ (HO 0-2), i.e., moving arthroplasties, and (2) severe $\mathrm{HO}$ (HO 3-4), i.e., stiff or barely moving arthroplasties. Seven patients treated at 2 segments had one moving and one stiff segment. Those were excluded from the outcome analysis.

\section{Statistics}

Statistical analyses were performed in R, version 3.5.0 ( R Foundation for Statistical Computing, Vienna, Austria). Missing values were replaced with multiple imputation using chained equations [19], as implemented in the R package mice, generating 100 imputed data sets. Variables with missing values were imputed. The imputation models used were: predictive mean matching for numerical variables, logistic regression for dichotomous variables, and ordinal regression for ordinal variables. For imputation of $\mathrm{HO}$ at 2 years, this value should be equal or less than $\mathrm{HO}$ at 5 years.

For the analysis of predisposing factors that may influence occurrence of $\mathrm{HO}$, both univariate and multivariate analyses were done. The univariate analyses included age, sex, smoking, body mass index (BMI; <25; 25-30; $>30$ ),

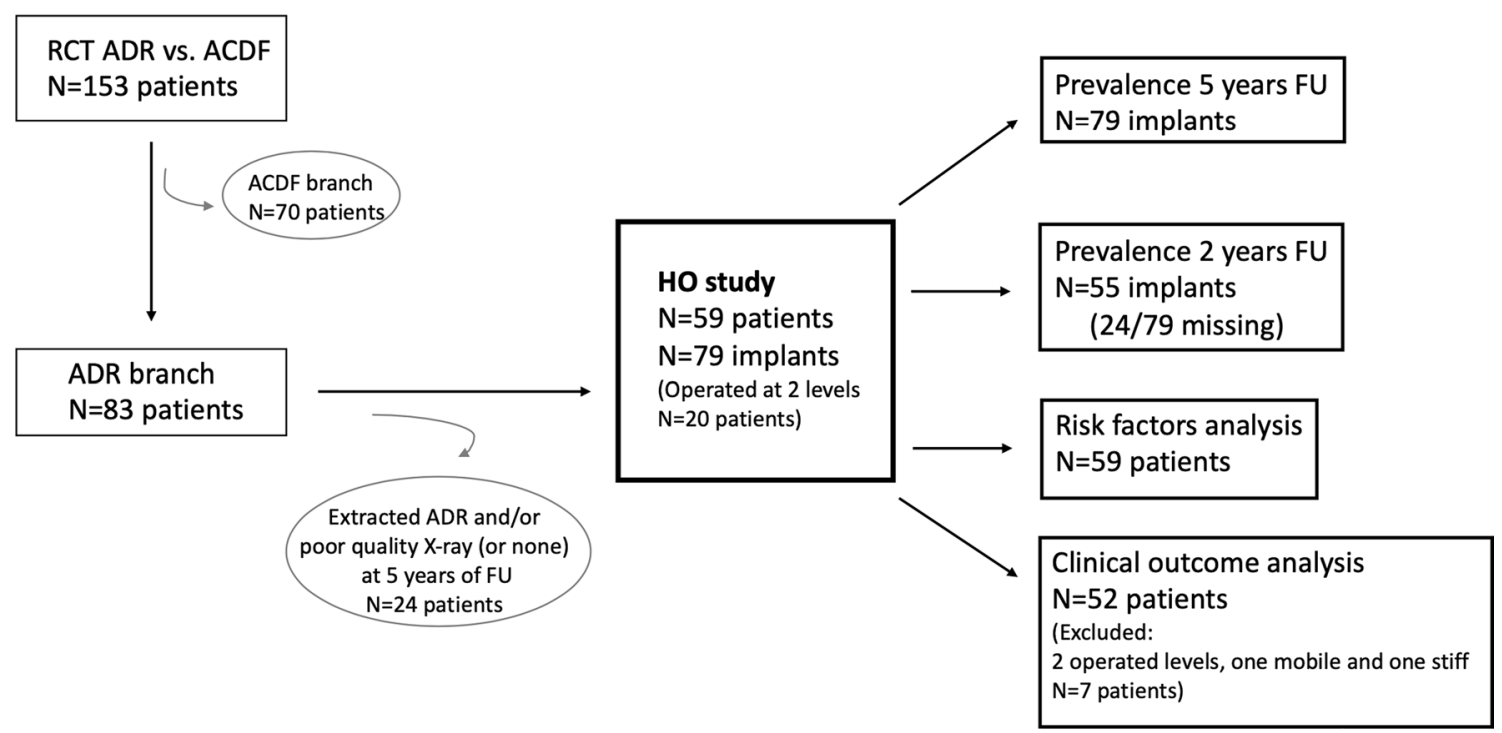

Fig. 1 Flowchart. $A C D F$ anterior cervical decompression and fusion, $A D R$ artificial disk replacement, $F U$ follow-up, $H O$ heterotopic ossification, $N$ number 

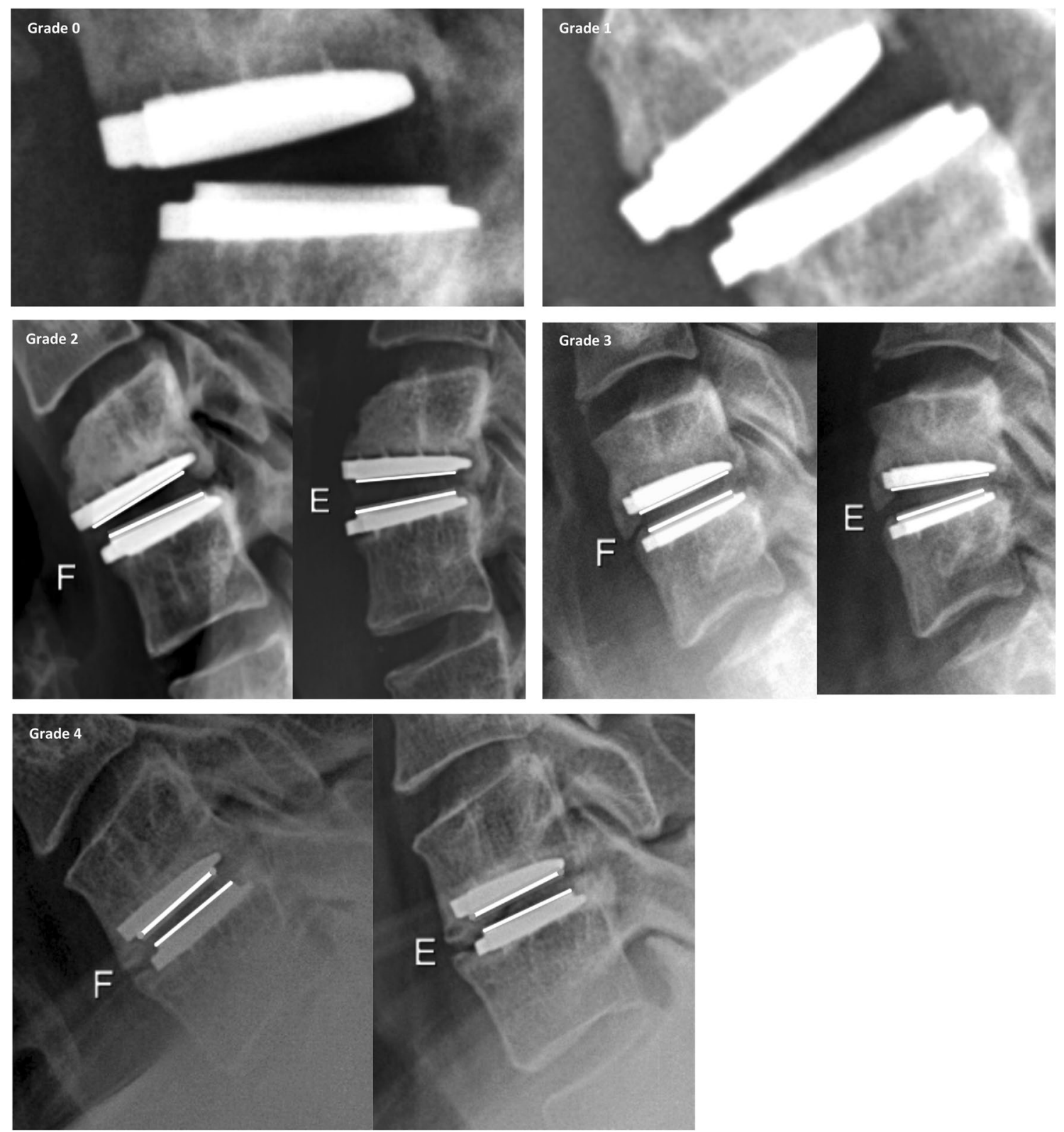

Fig. 2 McAfee Classification of Heterotopic Ossification (modified by Mehren/Suchomel). Grade 0: No HO present; Grade 1: HO detectable but not reaching the intervertebral space; Grade 2: HO reaching

facet arthropathy, preoperative adjacent disk degeneration, and centering of the ADR. The multivariate analysis used sex, age, smoking and BMI as potential factors. As the predisposing factors are patient-related variables, the analysis was patient- and not ADR-based. In cases with two surgically treated segments in the same patient, and different grades of $\mathrm{HO}$ in the two segments, the worse grade was included in the analysis. When the grade of HO was the same, the level to include in the analysis was chosen at random. The number and location of operated segments could therefore not be appreciated as eventual the intervertebral space; Grade 3: Bridging ossifications still allowing some movement at the segment; Grade 4: Complete fusion of the segment, without detectable movement; $\mathrm{HO}$ heterotopic ossification

predisposing factors in the risk analysis. For ordinal predictors, such as adjacent disk degeneration, we fitted an additional model, using equidistant scores. This corresponds to converting the variable to a numerical one with values $1,2,3$, etc., to gain power and interpretability by estimating a single odds ratio (OR) instead of one for each level. To analyze the impact of surgeon as a predisposing factor, a simple significance test was performed, comparing $\mathrm{HO}$ to surgeon, treating the former as ordinal and the latter as nominal. The test was done as a permutation test, using the R package coin. 
To analyze predictors affecting the progression of $\mathrm{HO}$ a univariate analyses (logistic regression) was done, using sex, age, smoking, preoperative adjacent disk degeneration, facet arthropathy at the index level, and centering of the ADR. For patients with arthroplasties at 2 segments, $\mathrm{HO}$ was considered to have progressed if at least one of the operated segments had increased; in cases where there were different degrees of progression in the two operated segments, the one that had progressed more was considered in the analysis. A multivariate analysis was then done, adjusting the variables sex, age, smoking and BMI to each other, to study their independent predictive value.

For the clinical outcome analysis, a linear regression model was fitted on imputed data, with NDI at 5 years of follow-up as the outcome, and dichotomized $\mathrm{HO}$ and baseline NDI as independent variables. The regression coefficient for $\mathrm{HO}$ was extracted. Regression coefficient, $95 \%$ confidence interval (CI) and $p$ value were calculated for the null hypothesis of no predictive effect on outcome. The regression coefficient can be interpreted as the difference in 5 -year NDI between the two HO groups, adjusted for baseline NDI. Thus, a positive value would correspond to larger NDI values in the severe $\mathrm{HO}$ group compared with the light or no $\mathrm{HO}$ group.

\section{Results}

\section{Missing values}

There were no missing values for $\mathrm{HO}$ at the 5-year followup. For $\mathrm{HO}$ at the 2-year follow-up, there were missing values for 24/79 ADRs. Three NDI values at 5 years were missing.

\section{Prevalence of heterotopic ossification (based on implants)}

\section{Prevalence at 2 years of follow-up}

Of the 55 arthroplasties where it was possible to evaluate $\mathrm{HO}$ at 2 years of follow-up, $\mathrm{HO}$ was present in $84 \%$. Severe HO (grade 3 or 4 ) occurred in $49 \%$, and complete fusion (grade 4 ) in $16 \%$ (Table 2).

\section{Prevalence at 5 years of follow-up}

Heterotopic ossification was present in $92 \%$ of the 79 arthroplasties at 5 years of follow-up. Severe HO (grade 3 or 4 ) existed in $71 \%$, and complete fusion (grade 4 ) in $27 \%$ (Table 2).
Table 2 Prevalence of $\mathrm{HO}$ at 2 and 5 years of follow-up

\begin{tabular}{llll}
\hline HO grade & $2 \mathrm{y}[n(\%)]$ & $5 \mathrm{y}[n(\%)]$ & $\begin{array}{l}5 \text { years, no or light } \\
\text { vs. severe HO }(\%)\end{array}$ \\
\hline 0 & $9(16.4 \%)$ & $6(7.6 \%)$ & 29 \\
1 & $2(3.6 \%)$ & $1(1.3 \%)$ & \\
2 & $17(30.9 \%)$ & $16(20.3 \%)$ & \\
3 & $18(32.7 \%)$ & $35(44.3 \%)$ & 71 \\
4 & $9(16.4 \%)$ & $21(26.6 \%)$ & \\
ADR implants & $55(100 \%)$ & $79(100 \%)$ & 100 \\
{$[n(\%)]$} & & & \\
\hline
\end{tabular}

Prevalence of HO in ADR implants, based on raw (non-imputed) data $A D R$ artificial disk replacement, $H O$ heterotopic ossification, $n$ number; \% percent; 2 y, 2 years of follow-up; 5 y, 5 years of follow-up

\section{Progression of Heterotopic Ossification ( 2 to 5 years of follow-up) (based on implants)}

Slightly over $1 / 3$ of the arthroplasties (36\%) increased in HO grade between 2 and 5 years of follow-up. Severe progression (increase in grade by 2 or more) occurred in $7 \%$ of arthroplasties.

\section{Predisposing factors to heterotopic ossification (at 5 years of follow-up) (based on patients)}

In the univariate analysis, male sex was a strong predictor for $\mathrm{HO}(\mathrm{OR}=9.86, p<0.001)$. Age was a predictor $(\mathrm{OR}=2.14$, $p=0.041)$ and $\mathrm{BMI}>30$ was at the threshold $(\mathrm{OR}=4.27$, $p=0.051)$. Neither smoking, preoperative ASP, facet arthropathy at the index level, nor centering of the ADR device had predictive value. No correlation was found between surgeon and $\mathrm{HO}$. When stratifying $\mathrm{HO}$ by the number of operated segments, more severe $\mathrm{HO}$ was found in patients with two operated segments $(p=0.032)$.

In the multivariate analysis, sex remained a strong predictor for $\mathrm{HO}(\mathrm{OR}=8.87, p<0.001)$, while age and BMI lost significance as predisposing factors (Table 3 ).

\section{Predisposing factors to progression of heterotopic ossification (based on patients)}

In the univariate analysis, no variable was identified as having predictive value. In the multivariate analysis no significant predisposing factors were identified in those patients whose $\mathrm{HO}$ had worsened, though smoking was at the threshold, possibly representing a trend (odds ratio $=3.95, p=0.055$ ).

\section{Clinical outcomes}

No difference in NDI was found between patients with severe $\mathrm{HO}$ and those with light or no HO. The regression coefficient was -9.3 , with $95 \% \mathrm{CI}-21.1$ to 2.5 and $p=0.12$. 
Table 3 Multivariate analysis of predisposing factors to $\mathrm{HO}$

\begin{tabular}{lllllll}
\hline Variable & Type & Reference & Level & OR & $95 \%$ CI & $p$ value \\
\hline Sex & Dichotomous & Female & Male & $\mathbf{8 . 8 7}$ & $(2.45,32.14)$ & $<\mathbf{0 . 0 0 1}$ \\
Age (decades) & Numerical & - & - & 1.94 & $(0.87,4.32)$ & 0.11 \\
Smoking & Nominal & Non-smoker & Smoker & 1.15 & $(0.37,3.56)$ & 0.80 \\
BMI (preoperative) & Nominal & BMI $<25$ & BMI 25-30 & 0.87 & $(0.24,3.15)$ & 0.83 \\
& & & BMI $>30$ & 2.05 & $(0.43,9.76)$ & 0.37 \\
\hline
\end{tabular}

$B M I$ body mass index, $C I$ confidence interval, $H O$ heterotopic ossification, $O R$ odds ratio

\section{Discussion}

Heterotopic ossification is an unintended phenomenon that occurs in cervical ADR and may lead to fusion. The term heterotopic ossification is, however, misleading. Heterotopic ossification is by definition the formation of bone outside the skeletal system [20]. In the case of cervical arthroplasty, $\mathrm{HO}$ refers to the formation of bone spurs at the disk level, i.e., the skeletal system. Such ossification could therefore represent a progression of an intrinsic degenerative process of natural aging, rather than a complication of surgery itself. The term has, however, fallen into general use in the specialized literature, and we therefore use it referring to bone formation in connection with an arthroplasty device.

\section{Motion preservation and ASP}

The loss of segmental motion did not affect the condition of adjacent levels, i.e., ASP, in this cohort of patients, as previously published [12].

\section{Prevalence of $\mathrm{HO}$}

There is a wide range of $\mathrm{HO}$ prevalence reported, ranging from $0 \%$ in a study of active duty military subjects in the USA [3] to $100 \%$ in a multicenter study performed in Norway [4], both studies with 2 years of follow-up. In a metaanalysis by Kong et al. [21], HO ranges from 16 to $86 \%$, with follow-ups from 1 to 10 years.

It is not clear why there is such a wide range of prevalence. One factor, as Kong suggests, could be interobserver error. When observing images and grading $\mathrm{HO}$, detection sensitivity would be different among authors in the various institutes.

Even in high-quality randomized controlled studies, bias may lead to unreproducible results. Research findings are less likely to be true in studies conducted in a small field, with greater flexibility in designs, definitions, outcomes, analytic modes and when there are greater financial and other interests involved [22]. In a meta-analysis published by
Yang et al. [23], only 3/38 included studies had low risk of bias, and all others showed intermediate or high risk of bias.

Our multicenter RCT was conducted outside IDE (investigational device exemption) conditions and was blinded until the moment of implant. The results were not positive to the "new" device. The sponsors were not involved in the study design, conduct of the trial, data analysis, interpretation of the results or the writing of the manuscript. There is therefore a lesser risk for publication, external validity, confirmation or financial conflict of interest bias, the four sources of bias defined by Radcliff et al. [24].

We found a prevalence of $\mathrm{HO}$ of $84 \%$ at 2 years and $92 \%$ at 5 years of follow-up. The patients with their ADRs removed due to loosening/subsidence were excluded as we unfortunately could not evaluate $\mathrm{HO}$ in those patients. It is likely that the patients with loosening/subsidence have less tendency to ossify, and by excluding them, the patients with ossification accumulate among the remaining patients, leading to a possible overestimation of $\mathrm{HO}$.

\section{Progression of $\mathrm{HO}$}

Progression of HO presented in the literature focuses on the increase in prevalence [5, 6]. In our study, we analyzed increase in grade of $\mathrm{HO}$, i.e., aggravation at a given operated segment. HO progressed between 2 and 5 years of follow-up in about $1 / 3$ of the ADRs.

\section{Predisposing factors to occurrence of $\mathrm{HO}$}

Significantly more HO, and of higher grades, was found in men. One possible explanation is that the same hormonal factors that contribute to a higher rate of osteoporosis [25] in women might protect them from excessive ossification.

No other significant predisposing factors to $\mathrm{HO}$ were found in our study.

Age and BMI seemed to be predisposing factors for $\mathrm{HO}$, but lost significance in a multivariate analysis. The odds ratio for age is similar in the uni- and multivariate analyses. It is possible that with a larger sample size the $p$ value for age would remain significant after adjusting. Age merits, therefore, further investigation as a potential predisposing factor to HO. 
It is also plausible to argue that age leads to more degenerated levels, and two treated levels have higher risk of HO than single levels. Two levels surgery might therefore be a co-variability. One other possible explanation for the twolevel positive predictor is that those patients with a tendency to have degenerative disease at several segments also have a tendency to grow bony spurs, i.e., develop more HO. The $\mathrm{HO}$ would therefore be related to the patient's biology and not the number of levels operated. Another factor leading to more $\mathrm{HO}$ in patients with ADR at 2 segments may be a disharmony between the motion of the operated segments and the motion of the patients' total cervical spine, which is probably more rigid than the operated segments, due to generalized degenerative disk disease.

Zhou et al. found a correlation between preoperative spondylosis and postoperative ossification [9], which was not the case in our study, where neither facet arthropathy at the index level nor degeneration at adjacent levels were identified as predisposing factors.

Yi et al., in a retrospective study including 170 patients and 3 different arthroplasty devices, identified male sex and type of artificial disk device as predisposing factors to HO [8]. In our study, all patients received the same type of device, which precludes an analysis of type of arthroplasty device as a potential risk factor to $\mathrm{HO}$.

In our study, the centering of the device was not a predisposing factor to HO. Yang et al. found that the amount of residual exposed endplate $(>2 \mathrm{~mm})$ is a risk factor for $\mathrm{HO}$ $(\mathrm{OR}=4.5)$, suggesting that maximizing the implant-endplate interface might diminish the risk for ossification [7].

\section{Predisposing factors to progression of $\mathrm{HO}$}

No factors were identified that could explain a tendency toward the progression (i.e., aggravation) of HO. Smoking is related to disk degeneration [26], and may therefore be expected to contribute to progression of HO. Although smoking did not, in our study, reach significance as a predisposing factor to progression of $\mathrm{HO}$ (odds ratio $=3.95$, $p=0.055$ ), that might be explained by a small sample size, and therefore we believe that it merits further investigation.

\section{Clinical outcomes}

In our study, clinical outcomes 5 years after surgery were not affected by the presence of severe HO. This is consistent with previous reports $[4,10]$, and until now there are no publications implying that preserved movement or unintended fusion affect clinical outcomes. The fact that an ADR is fused, thus not fulfilling its role as a motion device, does not have any clinical impact.

\section{Limitations}

The impossibility to analyze those patients whose ADRs had been removed may have led to analyzing bias and possibly an overestimation of $\mathrm{HO}$ in our study, as we did not analyze the intention-to-treat ADR group but the per-protocol ADR group.

It is possible that with a larger sample factors such as age or smoking might have reached significance as risk factors to the occurrence or progression of $\mathrm{HO}$.

All patients received the same type of device, therefore type of arthroplasty device could not be analyzed as a potential risk factor to HO.

\section{Conclusion}

Almost all ADR implants in our study have $\mathrm{HO}$ at 5 years of follow-up. Male sex is a clear risk factor. Prevalence increases slightly but in most arthroplasties HO does not progress after 2 years. Severe $\mathrm{HO}$ does not affect clinical outcome. Thus, having a functioning arthroplasty does not have a clinical impact.

Acknowledgements The authors thank Uppsala Clinical Research Center (UCRO), Lars Lindhagen, for statistical assistance; Stockholm Spine Center, Anna Arvidsson, and Eva Gulle, for collecting/handling data and assisting at all times; and Hospital of Jönköping, Håkan Löfgren, and Ludek Vavruch, for contributing with patients and collecting data.

Author contributions All authors contributed to the study conception and design. Material preparation, data collection and analysis were performed by Catarina Marques, Anna MacDowall, Martin Skeppholm, Nuno Canto Moreira and Claes Olerud. The first draft of the manuscript was written by Catarina Marques and all authors commented on previous versions of the manuscript. All authors read and approved the final manuscript.

Funding Open Access funding provided by Uppsala University. Study supported by unrestricted grants from the Stockholm County Council, DePuy Synthes Spine (325 Paramount Drive Raynham, MA 02767), Uppsala County Council and Swedish Society of Spinal Surgeons. The terms were set such that the sponsors would not be involved in the study design, conduct of the trial, data analysis, interpretation of the results or the writing of the manuscript. The sponsors have not read the manuscript before submission.

Code availability Not applicable.

\section{Compliance with ethical standards}

Ethics approval Trial approved by the local Swedish ethics review board. Study registered at ISRCTN (registration number: 44347115).

Conflict of interest CM, AM, MS, NCM: None. CO: Research grants: CSRS-E, DePuy Synthes; Speaker's bureau: AO Spine, DePuy Synthes, Medtronic; Board: CSRS-E. 
Consent to participate and consent for publication All participants provided oral and written informed consent.

Availability of data and material Data and material are available if necessary.

Open Access This article is licensed under a Creative Commons Attribution 4.0 International License, which permits use, sharing, adaptation, distribution and reproduction in any medium or format, as long as you give appropriate credit to the original author(s) and the source, provide a link to the Creative Commons licence, and indicate if changes were made. The images or other third party material in this article are included in the article's Creative Commons licence, unless indicated otherwise in a credit line to the material. If material is not included in the article's Creative Commons licence and your intended use is not permitted by statutory regulation or exceeds the permitted use, you will need to obtain permission directly from the copyright holder. To view a copy of this licence, visit http://creativecommons.org/licenses/by/4.0/.

\section{References}

1. Bartels RH, Donk R (2005) Fusion around cervical disc prosthesis: case report. Neurosurgery 57:E194. https://doi.org/10.1227/01. neu.0000163419.59635.78 (discussion E194)

2. Parkinson JF, Sekhon LH (2005) Cervical arthroplasty complicated by delayed spontaneous fusion. Case report. J Neurosurg Spine 2:377-380. https://doi.org/10.3171/spi.2005.2.3.0377

3. Zarkadis NJ, Cleveland AW, Kusnezov NA, Dunn JC, Caram PM, Herzog JP (2017) Outcomes following multilevel cervical disc arthroplasty in the young active population. Mil Med 182:e1790 e1794. https://doi.org/10.7205/MILMED-D-16-00085

4. Sundseth J, Jacobsen EA, Kolstad F, Sletteberg RO, Nygaard OP, Johnsen LG, Pripp AH, Andresen H, Fredriksli OA, Myrseth E, Zwart JA (2016) Heterotopic ossification and clinical outcome in nonconstrained cervical arthroplasty 2 years after surgery: the Norwegian Cervical Arthroplasty Trial (NORCAT). Eur Spine J 25:2271-2278. https://doi.org/10.1007/s00586-016-4549-6

5. Lee SE, Chung CK, Jahng TA (2012) Early development and progression of heterotopic ossification in cervical total disc replacement. J Neurosurg Spine 16:31-36. https://doi. org/10.3171/2011.8.SPINE11303

6. Xu S, Liang Y, Zhu Z, Wang K, Liu H (2019) Effectiveness evaluation of Prodisc-C prosthesis for more than 10 years follow-up after total cervical disc replacement. Zhongguo Xiu Fu Chong Jian Wai Ke Za Zhi 33:393-402. https://doi.org/10.7507/10021892.201810109

7. Yang MMH, Ryu WHA, Casha S, DuPlessis S, Jacobs WB, Hurlbert RJ (2019) Heterotopic ossification and radiographic adjacent-segment disease after cervical disc arthroplasty. J Neurosurg Spine. https://doi.org/10.3171/2019.5.SPINE19257

8. Yi S, Shin DA, Kim KN, Choi G, Shin HC, Kim KS, Yoon DH (2013) The predisposing factors for the heterotopic ossification after cervical artificial disc replacement. Spine J 13:1048-1054. https://doi.org/10.1016/j.spinee.2013.02.036

9. Zhou F, Ju KL, Zhao Y, Zhang F, Pan S, Heller JG, Sun Y (2018) Progressive bone formation after cervical disc replacement: minimum of 5-year follow-up. Spine (Phila Pa 1976) 43:163-170. https://doi.org/10.1097/BRS.0000000000002264

10. Yang X, Bartels R, Donk R, Depreitere B, Walraevens J, Zhai Z, Vleggeert-Lankamp CLA (2019) Does heterotopic ossification in cervical arthroplasty affect clinical outcome? World Neurosurg. https://doi.org/10.1016/j.wneu.2019.07.187

11. Skeppholm M, Lindgren L, Henriques T, Vavruch L, Lofgren H, Olerud C (2015) The discover artificial disc replacement versus fusion in cervical radiculopathy - a randomized controlled outcome trial with 2-year follow-up. Spine J 15:1284-1294. https:// doi.org/10.1016/j.spinee.2015.02.039

12. MacDowall A, Canto Moreira N, Marques C, Skeppholm M, Lindhagen L, Robinson Y, Lofgren H, Michaelsson K, Olerud C (2019) Artificial disc replacement versus fusion in patients with cervical degenerative disc disease and radiculopathy: a randomized controlled trial with 5-year outcomes. J Neurosurg Spine. https://doi.org/10.3171/2018.9.SPINE18659

13. Mehren C, Suchomel P, Grochulla F, Barsa P, Sourkova P, Hradil J, Korge A, Mayer HM (2006) Heterotopic ossification in total cervical artificial disc replacement. Spine (Phila Pa 1976) 31:2802-2806. https://doi.org/10.1097/01.brs.0000245852.70594 .d5

14. Walraevens J, Liu B, Meersschaert J, Demaerel P, Delye H, Depreitere B, Vander Sloten J, Goffin J (2009) Qualitative and quantitative assessment of degeneration of cervical intervertebral discs and facet joints. Eur Spine J 18:358-369. https://doi.org/10.1007/ s00586-008-0820-9

15. Miyazaki M, Hong SW, Yoon SH, Morishita Y, Wang JC (2008) Reliability of a magnetic resonance imaging-based grading system for cervical intervertebral disc degeneration. J Spinal Disord Tech 21:288-292. https://doi.org/10.1097/BSD.0b013e31813c0e59

16. Vernon H, Mior S (1991) The Neck Disability Index: a study of reliability and validity. J Manipulative Physiol Ther 14:409-415

17. Young IA, Cleland JA, Michener LA, Brown C (2010) Reliability, construct validity, and responsiveness of the neck disability index, patient-specific functional scale, and numeric pain rating scale in patients with cervical radiculopathy. Am J Phys Med Rehabil 89:831-839. https://doi.org/10.1097/PHM.0b013e3181ec98e6

18. Parker SL, Godil SS, Shau DN, Mendenhall SK, McGirt MJ (2013) Assessment of the minimum clinically important difference in pain, disability, and quality of life after anterior cervical discectomy and fusion: clinical article. J Neurosurg Spine 18:154-160. https://doi.org/10.3171/2012.10.SPINE12312

19. White IR, Royston P, Wood AM (2011) Multiple imputation using chained equations: issues and guidance for practice. Stat Med 30:377-399. https://doi.org/10.1002/sim.4067

20. McCarthy EF, Sundaram M (2005) Heterotopic ossification: a review. Skeletal Radiol 34:609-619. https://doi.org/10.1007/ s00256-005-0958-z

21. Kong L, Ma Q, Meng F, Cao J, Yu K, Shen Y (2017) The prevalence of heterotopic ossification among patients after cervical artificial disc replacement: a systematic review and meta-analysis. Medicine (Baltimore) 96:e7163. https://doi.org/10.1097/ MD.0000000000007163

22. Ioannidis JP (2005) Why most published research findings are false. PLoS Med 2:e124. https://doi.org/10.1371/journ al.pmed.0020124

23. Yang X, Janssen T, Arts MP, Peul WC, Vleggeert-Lankamp CLA (2018) Radiological follow-up after implanting cervical disc prosthesis in anterior discectomy: a systematic review. Spine J 18:1678-1693. https://doi.org/10.1016/j.spinee.2018.04.021

24. Radcliff K, Siburn S, Murphy H, Woods B, Qureshi S (2017) Bias in cervical total disc replacement trials. Curr Rev Musculoskelet Med 10:170-176. https://doi.org/10.1007/s12178-017-9399-2

25. Riggs BL, Khosla S, Melton LJ 3rd (1998) A unitary model for involutional osteoporosis: estrogen deficiency causes both type I and type II osteoporosis in postmenopausal women and 
contributes to bone loss in aging men. J Bone Miner Res 13:763773. https://doi.org/10.1359/jbmr.1998.13.5.763

26. Chen Z, Li X, Pan F, Wu D, Li H (2018) A retrospective study: Does cigarette smoking induce cervical disc degeneration? Int $\mathrm{J}$ Surg 53:269-273. https://doi.org/10.1016/j.ijsu.2018.04.004
Publisher's Note Springer Nature remains neutral with regard to jurisdictional claims in published maps and institutional affiliations. 